\title{
Pathogenesis of Hepatic Steatosis in the Parenterally Fed Rat
}

\author{
R. I. Hall, J. P. Grant, L. H. Ross, R. A. Coleman, \\ M. G. Bozovic, and S. H. Quarfordt \\ Departments of Surgery, Medicine, and Pediatrics, Division of \\ Gastroenterology, Nutritional Support Service, and Pediatric \\ Metabolism, Duke University Medical Center and Veterans \\ Administration Hospital, Durham, North Carolina 27705
}

bstract. Hepatic steatosis frequently complicates total parenteral nutrition (TPN). Some of the mechanisms responsible were examined in rats receiving calories as dextrose (CHO-TPN) or dextrose plus lipid emulsion (Lipid-TPN). Hepatic triglyceride content increased approximately threefold after CHO-TPN and twofold after Lipid-TPN $(P<0.02)$. Hepatic triglyceride fatty acid composition reflected endogenous synthesis. Hepatic acetyl-Coenzyme A carboxylase specific activity increased fourfold after CHO-TPN and twofold after Lipid-TPN, and it correlated positively with hepatic lipid content $(r=0.82)$. The activities of the microsomal enzymes of complex lipid synthesis were unchanged in the TPN groups.

Both TPN regimens suppressed hepatic triglyceride secretion, measured by the rise in plasma triglyceride and the incorporation of $\left[{ }^{14} \mathrm{C}\right]$ palmitic acid into plasma triglyceride after intravenous Triton. Hepatic triglyceride secretion correlated negatively with total hepatic lipid content $(r=-0.89)$.

CHO-TPN increased the uptake of a radiolabeled triglyceride emulsion and increased hepatic lipase activity, whereas Lipid-TPN decreased both. Both adipose and cardiac lipase were higher for Lipid-TPN animals than for CHO-TPN or control animals. Hepatic ${ }^{14} \mathrm{C}$-triglyceride content was increased in both TPN groups as compared with controls after the injection of $1-\left[{ }^{14} \mathrm{C}\right]-$ palmitic acid. This increment was proportional to the decreased hepatic secretion. Triglyceride fatty acid oxidation was significantly suppressed by CHO-TPN, less so by Lipid-TPN. Free fatty acid oxidation was suppressed only by CHO-TPN.

The results suggest that the steatosis induced by

Received for publication 14 November 1983 and in revised form 27 April 1984.

The Journal of Clinical Investigation, Inc.

Volume 74, November 1984, 1658-1668
TPN in rats was due to enhanced hepatic synthesis of fatty acid and reduced triglyceride secretion. Reduced hepatic triglyceride uptake, enhanced fatty acid oxidation, and enhanced peripheral tissue plasma triglyceride lipolysis when CHO-TPN is supplemented with lipid may modulate the accumulation of hepatic triglyceride and, along with reduced synthesis of fatty acid, lead to a lower hepatic triglyceride content.

\section{Introduction}

Since the first report that total parenteral nutrition (TPN) ${ }^{1}$ can sustain body composition and promote growth (1), it has become a routine practice in many medical centers. However, a number of complications have resulted from the use of TPN. One of the most frequent is hepatic dysfunction (2), especially in infants (3). Liver dysfunction may be manifested by biochemical disturbances such as hyperammonemia (4), elevations in serum transaminases and alkaline phosphatase (5), cholestasis (3), and hepatomegaly, usually as a result of fatty infiltration (6). In a few cases fibrosis (7) and cirrhosis (8) have occurred.

Two studies $(2,8)$ indicate that triglyceride infiltration of the liver may occur within a few days of starting TPN in adults and, particularly, in children. Examination of the liver from children who died after various periods on TPN has demonstrated a variety of histological changes including steatosis, cholestasis, bile duct proliferation, portal fibrosis, and, in one patient, cirrhosis (8). It has not been established that one abnormality inevitably progresses to the next, but steatosis appears to be the earliest and most frequent histological change noted.

The development of an increased hepatic triglyceride content as a consequence of TPN is not well understood. Suggested etiologies include amino acid imbalance (2), excessive dextrose

1. Abbreviations used in this paper: CoA, coenzyme A; CHO-TPN and Lipid-TPN, total parenteral nutrition regimens that provided all nonprotein energy as a dextrose or provided $33 \%$ of the nonprotein calories as a lipid emulsion, respectively; terms also describe animals fed on these regimens; TPN, total parenteral nutrition, total parenteral nutrition-fed. 
administration (9), presence of hepatotoxic amino acid metabolites (5), hyperglycemia (10), excessive lipid infusion (11), inadequate lipid infusion (12), and deficiencies of protein (13), essential fatty acids (14), or choline (15). A systematic examination of the pathogenesis of hepatic steatosis has not been reported.

Hepatic steatosis must result from an imbalance in the rate of entry and the rate of removal of fat from the liver. This imbalance may result from alterations in the rates of hepatic: (a) synthesis of fatty acids, as previously reported (15), and triglyceride; $(b)$ secretion of triglyceride or other compounds containing the fatty acyl moiety via plasma or bile; $(c)$ uptake of triglyceride and fatty acids; and/or $(d)$ triglyceride hydrolysis and fatty acid oxidation. Four of these mechanisms were examined in parenterally fed rats that were given two different TPN regimens that reflect the commonly used energy sources in clinical practice. One provided all nonprotein energy as dextrose (CHO-TPN) and the other provided $33 \%$ of the nonprotein calories as a lipid emulsion (Lipid-TPN).

\section{Methods}

TPN technique. Fisher 344 (Charles River Breeding Laboratories, Inc., Wilmington, MA) male rats weighing $180-200 \mathrm{~g}$ were used for all experiments. All operative procedures and fluid preparations were carried out under aseptic conditions.

Under intraperitoneal barbiturate anesthesia, the TPN rats were fitted with a superior vena cava catheter as described by Popp and Brennan (16). Infusions were controlled by Holter roller pumps (model 903; Criticon Inc., Tampa, FL), and the infused volume was increased over $24 \mathrm{~h}$ until the required amount of solution was being delivered. One group of animals was catheterized and offered oral chow ad lib. in order to measure the effect of the catheter on weight change and liver lipid. Two other groups were infused with identical volumes of differing concentrations of dextrose to determine the calorie load required for weight gain. After these pilot experiments, animals were randomized into three groups, one offered oral chow ad lib. (Purina

Table I. Nutritional Composition of TPN

Solutions Used in the Experimental Groups

\begin{tabular}{lcc}
\hline & Lipid-TPN & CHO-TPN \\
\hline Total nonprotein $(\mathrm{kcal} / \mathrm{ml})$ & 0.8 & 0.79 \\
Dextrose $(\mathrm{kcal} / \mathrm{ml})$ & 0.54 & 0.79 \\
Lipid $(\mathrm{kcal} / \mathrm{ml})^{*}$ & 0.26 & 0 \\
Nitrogen $(\mathrm{mg} / \mathrm{ml}) \ddagger$ & 6.29 & 6.29 \\
kcal $/ \mathrm{g}$ nitrogen & 127 & 127 \\
Infused volume $(\mathrm{ml} / 100 \mathrm{~g}$ per $d)$ & 36.3 & 36.3 \\
\end{tabular}

Each liter of fluid also contained calcium gluconate, $1 \mathrm{~g}$; potassium chloride, $5.2 \mathrm{~g}$; sodium chloride, $1.9 \mathrm{~g}$; sodium lactate, $16 \mathrm{meq}$; magnesium sulfate, $0.1 \mathrm{~g}$; and multiple vitamins concentrate, $10 \mathrm{ml}$ (Armour Pharmaceuticals, Tarrytown, NY).

* Liposyn 20\% and $\ddagger$ Aminosyn $8.5 \%$ (Abbott Laboratories, Hospital Product Div.).
Lab Chow; Ralston Purina Co., St. Louis, MO), a second given TPN with carbohydrate and amino acids, and a third given TPN with carbohydrate, amino acids, and lipid (Liposyn; Abbott Laboratories, Hospital Product Div., North Chicago, IL). Both TPN groups were provided with identical calories and quantities of protein, electrolytes, and vitamins (Table I). All nutritional regimes were administered for $7 \mathrm{~d}$. Experimental and control animals were housed in identical metabolic cages under controlled environmental conditions. The nutritional intake of the control group was estimated from the weight of chow eaten each day. Urine was collected during the final $5 \mathrm{~d}$ of TPN from 20 animals in each TPN group, and total urinary nitrogen was measured by an automated Kjeldahl method (17). The percentage of administered nitrogen retained over $5 \mathrm{~d}$ was calculated from the urinary nitrogen and the quantity of infused nitrogen. Fecal losses were minimal after $24 \mathrm{~h}$ and were ignored.

On the morning of the seventh day, each animal was briefly anesthetized with methoxyflurane vapor (Abbott Laboratories, Hospital Product Div.), and a jugular or femoral vein catheter was inserted to administer isotopes or collect blood samples according to protocol. The volume of injected isotope in each experiment was $0.25 \mathrm{ml} / 100 \mathrm{~g}$ body wt. Animals had fully recovered from this short-acting anesthetic before the experimental protocol was begun. They were killed by exsanguination via the aorta under methoxyflurane anesthesia.

Chemical analysis. In all cases total liver lipid content was measured by homogenization of all or part of the organ in a modified Dole's extraction mixture (18) using petroleum ether instead of heptane. Aliquots of the organic phase were dried to a constant weight to allow measurement of the total extractable lipid content of the liver. Plasma lipids were also extracted in modified Dole's mixture. Triglycerides in plasma or liver extracts were measured by an automated fluorimetric technique (19), and phospholipids were calculated from the lipid phosphorus measured by the method of Ames and Dubin (20). Radioactivity in plasma or liver extracts was measured by drying aliquots of the extract and redissolving them in a toluene-based scintillation cocktail. All samples were counted in a scintillation counter (LS350; Beckman Instruments Inc., Fullerton, CA) under single or double labeled conditions as appropriate. Quenching was assessed by internal standardization, with the initial addition of appropriate ${ }^{14} \mathrm{C}$ - and then ${ }^{3} \mathrm{H}$-compounds. Aliquots of liver lipid extract from control and TPN animals were dried under nitrogen, dissolved in a chloroform/methanol $(2: 1, \mathrm{vol} / \mathrm{vol})$ mixture, and separated by thin-layer chromatography on silica gel-H plates with a solvent system of petroleum ether/diethyl ether/glacial acetic acid, (80:20:1, vol/vol). Triglyceride was identified by exposure to iodine vapor and compared with known standards. The silica gel was extracted again with chloroform/methanol (2:1, vol/vol), and the triglyceride was subsequently hydrolyzed and methylated by sealed tube hydrolysis after the addition of an internal standard of heptadecanoic acid (21). The fatty acid methyl esters were taken up in isooctane and identified by gas liquid chromatography with a Varian $\mathbf{3 7 0 0}$ instrument (Varian Associates, Palo Alto, CA) using a flame ionization detector, nitrogen carrier gas, and a 6-ft glass column packed with 10\% SP-2330 100/120 Chromosorb WAW (Supelco; Dell, PA). Peak areas were measured with a CDS III microprocessor (Varian Associates) against the internal standard.

Measurement of the enzymes of fatty acid, triacylglycerol, and phosphatidyl choline synthesis and catabolism. Animals were killed after $7 \mathrm{~d}$ of treatment with each nutritional regime and the livers were homogenized in ice-cold medium $(0.25 \mathrm{M}$ sucrose, $1 \mathrm{mM}$ EDTA, 10 $\mathrm{mM}$ Tris- $\mathrm{Cl}, \mathrm{pH}$ 7.4) with a motor-driven Teflon-glass homogenizer. The homogenate was centrifuged at $100,000 \mathrm{~g}$ for $1 \mathrm{~h}$. Acetyl-Coenzyme 
(CoA) carboxylase activity in the supernatant was determined by the method of Craig et al. (22). Microsomal enzyme activities were measured in the total particulate fraction. Protein concentrations were measured by the method of Lowry et al. (23), with bovine serum albumin as the standard.

Fatty acid CoA ligase activity was measured using $50 \mu \mathrm{M}$ $\left[{ }^{3} \mathrm{H}\right]$ palmitate and $5 \mathrm{~mm} \mathrm{ATP}$ as previously described (24). Glycerol$P$ acyltransferase activity was assayed using $75 \mu \mathrm{M}$ palmitoyl CoA and $300 \mu \mathrm{M}\left[{ }^{3} \mathrm{H}\right]$ glycerol 3-P (25). Lysophosphatidic acid acyltransferase activity was determined spectrophotometrically using $55 \mu \mathrm{M}$ oleoylglycerol-P and $50 \mu \mathrm{M}$ oleoyl-CoA (26). Phosphatidic acid phosphatase activity was measured by monitoring orthophosphate release using 1.0 $\mathrm{mM}$ phosphatidic acid (27). Diacylglycerol acyltransferase activity was assayed using $30 \mu \mathrm{M}\left[{ }^{3} \mathrm{H}\right]$ palmitoyl-CoA and $200 \mu \mathrm{M} S N$-1,2-diolein dispersed in acetone (28). Diacylglycerol cholinephosphotransferase activity was measured using $100 \mu \mathrm{M}\left[{ }^{14} \mathrm{C}\right]$ cytidine diphosphate choline and $100 \mu \mathrm{M}$ diolein dispersed in acetone (29). All isotopes were purchased from New England Nuclear (Boston, MA) except $\left[{ }^{14} \mathrm{C}\right]$ cytidine diphosphate choline, which was obtained from ICN K \& K Laboratories Inc. (Plainview, NY).

Three animals from each regime were given intravenous heparin $(10 \mathrm{U} / 100 \mathrm{~g}) 10 \mathrm{~min}$ before they were killed, and aortic blood was collected for measurement of protamine-insensitive lipase activity as previously described (30), except that a greater volume of plasma (25 $\mu$ l) was used. Other groups of animals were killed without heparin injections, and specimens of their adipose tissue, skeletal muscle, and heart were extracted (30) and assayed for lipoprotein lipase by the method of Schotz (31). Aliquots of plasma were assayed with and without pre-incubation with protamine sulfate in order to measure the contribution of hepatic lipase to the total plasma activity.

Hepatic secretion of triglycerides. $2 \mathrm{~h}$ before sacrifice, each animal was given an intravenous injection of $0.5 \mathrm{ml}$ of a $20 \%$ solution of Triton WR1339 (Sigma Chemical Co., St. Louis, MO), in order to block peripheral tissue triglyceride uptake (32). 2 min later a blood sample was taken to measure base-line plasma triglyceride concentration. After $1 \mathrm{~h}$, each animal was given an intravenous bolus of $1-\left[{ }^{14} \mathrm{C}\right]$ palmitic acid in 3.0\% albumin solution and $1 \mathrm{~h}$ later the animals were killed. Plasma triglyceride mass was determined at death by the method described, and another plasma aliquot was extracted by the Dole method. The lipid extract was separated by thin-layer chromatography as described. More than $95 \%$ of the plasma radioactivity was in triglyceride. Hepatic triglyceride secretion was calculated from the mass determinations at $2 \mathrm{~min}$ and $2 \mathrm{~h}$ and also from the incorporation of radiolabeled palmitate into plasma triglyceride. The latter probably gives a better indication of hepatic secretion than do the mass data, which may reflect both hepatic and intestinal contributions (32).

Hepatic uptake and metabolism of plasma triglyceride and fatty acid. A triolein emulsion labeled with $2-\left[{ }^{3} \mathrm{H}\right]$ glycerol triolein and glycerol $1-\left[{ }^{14} \mathrm{C}\right]$ triolein (Amersham Corp., Arlington Heights, IL) was prepared as described by Shelburne et al. (33). Each animal received $1 \mathrm{mg}$ of emulsion triglyceride per $100 \mathrm{~g}$ body wt by an intravenous injection. Expired ${ }^{14} \mathrm{CO}_{2}$ was collected by placing the rats in sealed metabolic cages through which air was drawn at a constant rate. The expired gas was passed through each of two flasks containing $10 \mathrm{ml}$ Oxifluor (New England Nuclear) in which the ${ }^{14} \mathrm{CO}_{2}$ was trapped and subsequently counted. The placement of a third flask in series demonstrated that this system collected $>96 \%$ of the extracted ${ }^{14} \mathrm{CO}_{2}$. After $20 \mathrm{~min}$, the animals were killed, and the liver and samples of skeletal muscle, adipose tissue, and heart were rapidly removed and frozen. Uptake of triglyceride by the liver and widely varying areas of skeletal muscle, adipose tissue, and heart, was determined by measurement of the radiolabeled content of the organic phase of a Dole extract of each tissue under double labeled conditions with internal standardization as described. For measurements of fatty acid metabolism, a solution containing $40 \mathrm{nmol}$ and $2 \mu \mathrm{Ci}$ of $1-\left[{ }^{14} \mathrm{C}\right]$ palmitic acid/ml in $3 \%$ albumin was administered intravenously and the animals were placed in sealed metabolic cages. ${ }^{14} \mathrm{CO}_{2}$ was collected as described with the exception that $125 \mathrm{ml}$ of $10 \% \mathrm{NaOH}$ was used in each flask as the trapping agent. 2-ml aliquots of this were counted in $15 \mathrm{ml}$ of Aquasol II (New England Nuclear) and $7 \mathrm{ml}$ water. These animals were killed $1 \mathrm{~h}$ after the injection of $1-\left[{ }^{14} \mathrm{C}\right]$ palmitate and the livers were removed for analysis of total lipid and incorporation of ${ }^{14} \mathrm{C}$-fatty acid into liver lipid as previously described. Aliquots of the liver lipid extract were chromatographed in the neutral lipid system as described above. The triglyceride was identified by its migration with the standard and radioassayed.

Statistical analysis. All statistical analyses were performed by oneway analysis of variance. Correlation coefficients were calculated by the method of least squares.

\section{Results}

TPN with or without lipid supported weight gain in the rat (Table II, regimens 5 and 6) when a nonprotein calorie load of $\sim 29 \mathrm{kcal} / 100 \mathrm{~g}$ per $\mathrm{d}$ and a nitrogen intake of $230 \mathrm{mg} / 100$ $\mathrm{g}$ per $\mathrm{d}$ were provided. This approximates the caloric needs and exceeds the nitrogen intake recommended for rats of this size (34). The oral controls (regimen 1) consumed equivalent nonprotein calories $(83.7 \%$ from carbohydrate and $16.3 \%$ from fat) but more nitrogen than the TPN groups, owing to the high protein content of the chow (rough analysis, 22.5\% protein, $4.5 \%$ fat, and $52.1 \%$ carbohydrate with a $3.34 \mathrm{kcal} / \mathrm{g}$ physiological fuel value). The presence of the catheter in regimen 2 clearly influenced the amount of food eaten. The catheterized animals lost weight, but no effect was seen on the amount of total extractable hepatic lipids. As the carbohydrate calories were increased from 2.6 to $28.9 \mathrm{kcals} / 100 \mathrm{~g}$ per d (Table II, regimens 3-5), weight gain and positive nitrogen balance were achieved. The increment in carbohydrate calories needed to produce weight gain similar to that of controls was accompanied by a significant increase in hepatic lipid. Even when carbohydrate calories were given at levels insufficient to maintain weight (Table II, regimen 4), a $60 \%$ increase in hepatic lipid was observed.

The purpose of the study was to examine the effect of adequate TPN with nonprotein calories as carbohydrate or carbohydrate and lipid on liver lipid homeostasis and to compare it with results from control rats on a normal nutritional intake. All subsequent data are derived from comparisons of animals on CHO-TPN (regimen 5, Table II) and Lipid-TPN (regimen 6) with control chow-fed animals (regimen 1). The nutritional composition of these two TPN solutions (Table I) was identical in all respects except for the provision of onethird of the nonprotein calories as a safflower oil emulsion in Lipid-TPN. Rats on both TPN regimens gained weight similarly, although the gain was significantly less than that of controls. 
Table II. The Effect of $7 d$ of TPN with Differing Nutritional Regimens on Body Weight, Nitrogen Balance, and Total Liver Lipid Content

\begin{tabular}{|c|c|c|c|c|c|}
\hline Regimen & $\begin{array}{l}\text { Nonprotein } \\
\text { calorie intake }\end{array}$ & $\begin{array}{l}\text { Nitrogen } \\
\text { intake }\end{array}$ & Weight change & $\begin{array}{l}\text { Nitrogen } \\
\text { retention* }\end{array}$ & Total liver lipid \\
\hline & $\begin{array}{l}\text { kcal/100 g per } \\
d \pm S E M\end{array}$ & $\begin{array}{l}m g / 100 \mathrm{~g} p e r \\
d \pm S E M\end{array}$ & $g \pm S E M$ & $\% \pm S E M$ & $m g / g \pm S E M$ \\
\hline 1. Oral ad lib. $(n=23)$ & $31.2 \pm 1.58 \ddagger$ & $352.0 \pm 17.8$ & $16.5 \pm 3.0$ & & $37.4 \pm 0.6$ \\
\hline 2. Catheterized + oral ad lib. $(n=7)$ & & & $-4.9 \pm 2.65 \S$ & & $36.2 \pm 0.5$ \\
\hline 3. CHO-TPN $(n=14)$ & $2.6 \pm 0.05$ & $204.9 \pm 4.05$ & $-39.3 \pm 2.06 \S$ & & $29.0 \pm 1.7$ \\
\hline 4. CHO-TPN $(n=7)$ & $21.9 \pm 0.64$ & $194.4 \pm 5.10$ & $-4.5 \pm 2.01 \S$ & & $60.8 \pm 12.0$ \\
\hline 5. CHO-TPN $(n=31)$ & $28.9 \pm 0.23$ & $230.1 \pm 1.83$ & $6.2 \pm 1.30^{\prime \prime}$ & $18.2 \pm 1.2$ & $140.1 \pm 10.6 \pi$ \\
\hline 6. Lipid-TPN $(n=32)$ & $28.6 \pm 0.49$ & $224.9 \pm 3.85$ & $8.8 \pm 1.13^{\prime \prime}$ & $19.8 \pm 2.8$ & $101.6 \pm 7.2^{* *}$ \\
\hline
\end{tabular}

* Calculated as (administered $\mathrm{N}_{2}$ - urinary $\mathrm{N}_{2}$ )/administered $\mathrm{N}_{2}$ (percentage). ‡ Caloric intake of oral controls measured in six rats. $\S$ Different from regimen $1, P<0.0001$. "Different from regimen $1, P<0.05$. I Different from regimens $1,2,3$, and $4, P<0.001$. ** Different from regimens $1,2,3$, and $4, P<0.001$, and regimen $5, P<0.02$.

Both TPN regimens produced equally positive nitrogen balances. Hepatic lipid content increased approximately two- to threefold in rats on each TPN regimen (Table II, 5 and 6), but the steatosis was significantly less in the Lipid-TPN rats than in those receiving CHO-TPN.

Quantitation of hepatic lipids showed that the increased lipid found in the TPN animals was due to a rise in triglyceride content (Table III). The phospholipid content of the extract did not change significantly and was similar to levels previously reported in chloroform/methanol extracts of rat liver after TPN (15). This suggests that the modified Dole procedure adequately extracted the bulk of phospholipids. The close agreement between the total lipids and the sum of the triglyceride and phospholipid indicates that virtually all of the extracted material was in these two classes.

The fatty acid composition of the liver triglycerides (Table IV) differed between the TPN rats and controls. Only $0.5 \%$ of the triglyceride fatty acid in the CHO-TPN rats were linoleic, as compared with 14.9 and $17.0 \%$ in the control and LipidTPN rats, respectively. Owing to the larger total amount of

Table III. Analysis of Hepatic Lipid Extract after $7 d$ of TPN*

\begin{tabular}{lccc}
\hline Regimen & Total liver lipid & Phospholipid & Triglyceride \\
\hline Oral control & $37.4 \pm 0.42$ & $32.7 \pm 0.99$ & $8.4 \pm 0.75$ \\
& $(n=11)$ & $(n=5)$ & $(n=11)$ \\
Lipid-TPN & $110.2 \pm 7.91 \ddagger$ & $30.5 \pm 2.20$ & $84.7 \pm 8.72 \ddagger$ \\
& $(n=13)$ & $(n=6)$ & $(n=13)$ \\
CHO-TPN & $146.4 \pm 15.80 \ddagger$ & $28.1 \pm 1.92$ & $123.2 \pm 15.57 \ddagger$ \\
& $(n=12)$ & $(n=6)$ & $(n=12)$ \\
& & &
\end{tabular}

* All values are milligrams per gram wet weight \pm SEM.

$\ddagger$ Different from oral controls, $P<0.001$, and from each other, $P<0.05$. triglyceride in the CHO-TPN livers (Table III), however, the absolute amount of triglyceride linoleic acid per gram of liver was almost one-half that of controls. Similarly, the livers from both TPN groups contained larger absolute amounts of triglyceride palmitate and oleate than did controls. The very different fatty acid composition of Liposyn as compared with that of the hepatic triglycerides of the Lipid-TPN rats suggests that Liposyn emulsion did not simply accumulate in the liver. Nevertheless, the large amount of linoleic acid infused did result in an approximately 10 -fold increase in the amount of linoleic acid in the liver of the Lipid-TPN animals as compared with controls.

Assay of key hepatic enzymes in the synthesis of the complex lipids, phosphatidylcholine and triglyceride (Table V), revealed few differences between the TPN groups and the oral controls. The activity of phosphatidic acid phosphatase was significantly greater for the Lipid-TPN group than for the control, and that of diacylglycerol acyltransferase was also

Table IV. Fatty Acid Composition of Hepatic Triglycerides and Liposyn Emulsion after $7 d$ of TPN*

\begin{tabular}{lllll}
\hline Regimen & $16: 0$ & $18: 0$ & $18: 1$ & $18: 2$ \\
\hline $\begin{array}{c}\text { Oral control } \\
(n=6)\end{array}$ & $34.3 \pm 5.39$ & $6.7 \pm 0.84$ & $39.4 \pm 1.47$ & $14.9 \pm 4.50$ \\
$\begin{array}{c}\text { CHO-TPN } \\
(n=11)\end{array}$ & $41.6 \pm 1.75$ & $2.9 \pm 0.10 \S$ & $44.7 \pm 1.99$ & $0.5 \pm 0.11 \ddagger$ \\
$\begin{array}{c}\text { Lipid-TPN } \\
(n=13)\end{array}$ & $48.0 \pm 3.51 \ddagger$ & $2.9 \pm 0.23 \S$ & $26.5 \pm 1.11^{11}$ & $17.0 \pm 3.57$ \\
Liposyn & 7.0 & 2.5 & 13.0 & 77.0 \\
\hline
\end{tabular}

* All figures are mean percentages of total identified peaks \pm SEM. ‡ Different from oral, $P<0.05$.

$\S$ Different from oral, $P<0.001$.

"Different from oral, $P<0.001$, and from CHO-TPN, $P<0.001$.

I Data from Abbott Laboratories, Hospital Product. 
Table V. Specific Activities of Acetyl COA Carboxylase and of Enzymes of Triacylglycerol and Phosphatidylcholine Synthesis in Rat Liver after $7 d$ of Oral or TPN Feeding

\begin{tabular}{lccc}
\hline Regimen & Oral & CHO-TPN & Lipid-TPN \\
\hline & $n$ mol/min per mg protein & nmol/min per mg protein & $n$ mol/min per mg protein \\
Acetyl-CoA carboxylase* & $5.14 \pm 1.12$ & $20.19 \pm 1.14 \ddagger$ & $10.58 \pm 0.79 \S$ \\
Fatty acid CoA ligase & $38.76 \pm 4.10$ & $29.84 \pm 3.07$ & $32.08 \pm 2.64$ \\
Glycerol-P acyltransferase & $1.74 \pm 0.23$ & $1.90 \pm 0.09$ & $1.78 \pm 0.07$ \\
Lysophosphatidic acid acyltransferase & $30.74 \pm 0.65$ & $32.71 \pm 1.17$ & $36.71 \pm 2.39$ \\
Phosphatidic acid phosphatase & $5.40 \pm 0.30$ & $6.20 \pm 0.21$ & $7.08 \pm 0.26$ \\
Diacylglycerol acyltransferase & $4.22 \pm 0.31$ & $3.84 \pm 0.14$ & $4.79 \pm 0.15$ \\
Diacylglycerol cholinephosphotransferase & $2.66 \pm 0.10$ & $2.99 \pm 0.08$ & $2.31 \pm 0.19$ \\
Total hepatic supernatant protein" & $445.13 \pm 35.10$ & $481.63 \pm 9.67$ & $436.30 \pm 47.46$ \\
Total hepatic particulate protein" & $860.25 \pm 48.95$ & $779.92 \pm 29.36$ & $773.28 \pm 66.38$
\end{tabular}

Values are means \pm SEM of six determinations except lysophosphatidic acid acyl transferase (four determinations in oral and CHO-TPN rats). * Measured in supernatant; all other enzymes measured in particulate preparation. $\ddagger$ Different from oral and Lipid-TPN, $P<0.0001$. $\S$ Different from oral, $P<0.01$. "Total hepatic supernatant and particulate protein content (milligrams per liver).

significantly greater than for the CHO-TPN group; however, the activities of these enzymes did not correlate with the amount of hepatic triglyceride when all data were considered.

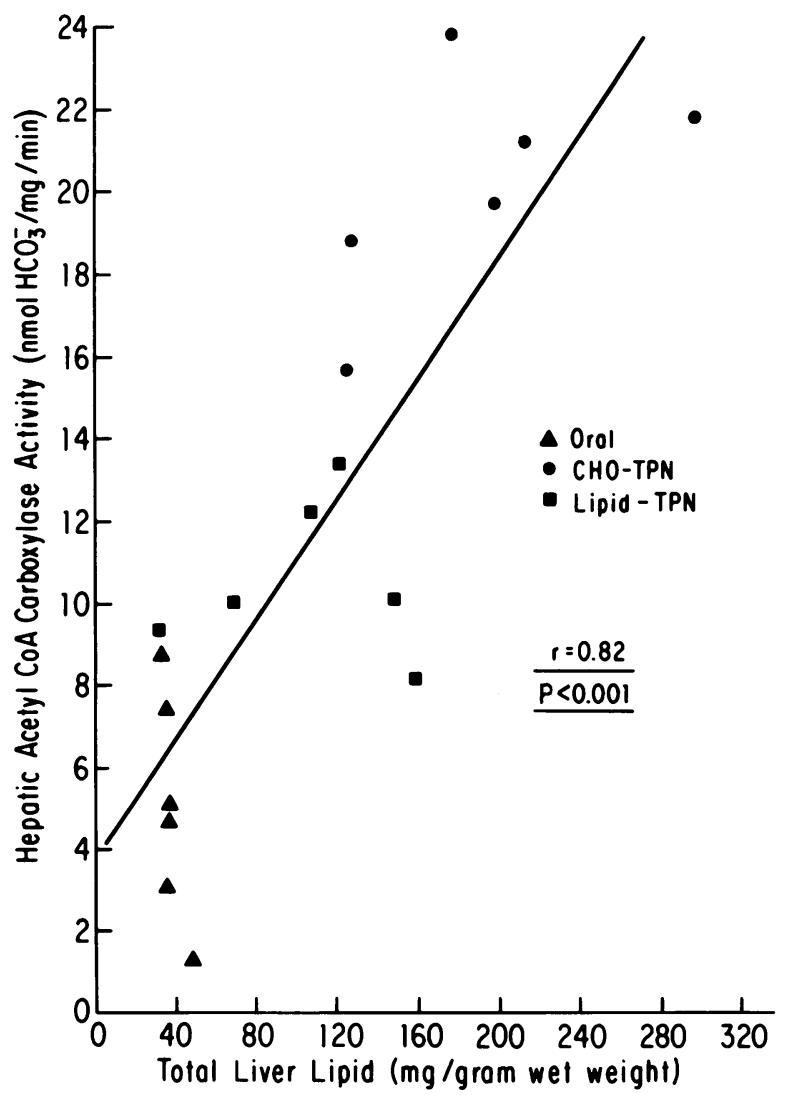

Figure 1. The relationship between hepatic acetyl-CoA carboxylase specific activity (nanomoles $\left[{ }^{14} \mathrm{C}\right] \mathrm{HCO}_{3}$ fixed per milligram protein per minute and total hepatic lipid content (milligrams per gram wet weight).
The Lipid-TPN groups demonstrated somewhat less activity for diacylglycerol cholinephosphotransferase, possibly as a consequence of the intravenous administration of an appreciable amount of phosphatidylcholine. The major difference in enzyme activity between TPN and control rats was in the regulatory enzyme for fatty acid synthesis, acetyl-CoA carboxylase. This increased fourfold after CHO-TPN and twofold after LipidTPN. The specific activity of acetyl-CoA carboxylase in all animals showed a high correlation with the total hepatic content of lipid (Fig. 1) with a correlation coefficient of 0.83 $(P<0.001)$.

Hepatic secretion of triglyceride was estimated from the rise in plasma triglycerides after administration an intravenous dose of Triton WR 1339 , and measured more specifically from the incorporation of $1-\left[{ }^{14} \mathrm{C}\right]$ palmitate into plasma triglyceride (Table VI). Both CHO-TPN and Lipid-TPN regimens resulted in a significantly reduced rise in plasma triglycerides as compared with controls, but this was less marked in the CHOTPN rats. The incorporation of $1-\left[{ }^{14} \mathrm{C}\right]$ palmitate into plasma triglyceride was also significantly reduced in both groups, each secreting less than one-half of the amount of labeled triglyceride found in controls. The Triton-induced rise in plasma triglyceride (Fig. $2 A$ ) and the percentage secretion of $1-\left[{ }^{14} \mathrm{C}\right]$ palmitate as ${ }^{14} \mathrm{C}$-triglyceride (Fig. $2 \mathrm{~B}$ ) correlated negatively with the hepatic lipid content ( $r=-0.72$ and -0.89 , respectively).

Despite the continuous infusion of triglyceride in the LipidTPN rats until $20 \mathrm{~min}$ before they were killed, the plasma triglyceride concentrations were not significantly different from those of either the controls or the CHO-TPN group (Table VII). The fractional recovery of radiolabeled triglyceride in plasma $20 \mathrm{~min}$ after the intravenous injection of $2 \mathrm{mg}$ of a 2 $\left[{ }^{3} \mathrm{H}\right]$ glycerol-1- $\left[{ }^{14} \mathrm{C}\right]$ triolein emulsion was considerably greater in the Lipid-TPN group than in either CHO-TPN or control animals. Separation of plasma lipid extracts by Schotz partition (31) demonstrated that $>90 \%$ of the plasma lipid ${ }^{14} \mathrm{C}$ was in triglyceride, with virtually none in free fatty acids. Plasma ${ }^{14} \mathrm{C}$ - 
Table VI. Changes in Plasma Triglycerides $2 \mathrm{~h}$ after Intravenous Injection of Triton WRI339,

and Percentage of Injected $1-\left[{ }^{14} \mathrm{C}\right]$ Palmitic Acid Secreted as Plasma Triglyceride during $I$ h by Tritonized Rats

\begin{tabular}{|c|c|c|c|c|}
\hline \multirow[b]{2}{*}{ Regimen } & \multicolumn{2}{|l|}{ Plasma triglycerides } & \multirow[b]{2}{*}{$\Delta$ Triglyceride } & \multirow{2}{*}{$\begin{array}{l}\% 1-\left[{ }^{14} \mathrm{C}\right] \mathrm{Palm} \text { mitic } \\
\text { acid in plasma triglyceride }\end{array}$} \\
\hline & $2 \mathrm{~min}$ after Triton & $122 \mathrm{~min}$ after Triton & & \\
\hline & $m g / d l \pm S E M$ & $m g / d l \pm S E M$ & $m g / d l$ & $\% / m l$ plasma $\pm S E M$ \\
\hline Oral controls $(n=6)$ & $43.8 \pm 11.2$ & $740.0 \pm 55.9$ & $697.0 \pm 46.1$ & $0.626 \pm 0.058$ \\
\hline CHO-TPN $(n=6)$ & $21.3 \pm 4.0$ & $530.3 \pm 50.5$ & $508.7 \pm 48.9^{*}$ & $0.253 \pm 0.048 \S$ \\
\hline Lipid-TPN $(n=6)$ & $81.7 \pm 2.3$ & $480.0 \pm 61.9$ & $398.3 \pm 60.3 \ddagger$ & $0.232 \pm 0.039 \S$ \\
\hline
\end{tabular}

* Different from oral, $P<0.05$. $\ddagger$ Different from oral, $P<0.01$. $\S$ Different from oral, $P<0.001$.

triglyceride present in excess of the ratio of the injected emulsion represented hepatic secretion of re-esterified triglyceride fatty acid. Secretion was significantly reduced in both TPN groups (Table VII) as compared with controls.

Although the Lipid-TPN group cleared triglyceride from the plasma significantly more slowly than did the other two groups, the recovery of ${ }^{14} \mathrm{C}$-lipid in the tissue extracts was appreciable (Table VIII). This group had significantly more ${ }^{14} \mathrm{C}$-lipid in skeletal muscle than did either of the other groups. Both TPN groups had appreciably more of the injected triglyceride fatty acid recovered in adipose tissue than did the oral control animals. The recovery of the triglyceride ${ }^{14} \mathrm{C}$-fatty acid in heart tissue was less for both TPN groups than for the oral controls but significantly so only in the CHO-TPN rats. The heart recoveries appeared to correlate better with the radiolabeled $\mathrm{CO}_{2}$ production than did recoveries from any of the other tissues examined, including the liver. Animals given CHO-TPN had significantly more ${ }^{3} \mathrm{H}$ in the liver lipid extracts $20 \mathrm{~min}$ after an injection of $2-\left[{ }^{3} \mathrm{H}\right]$ glycerol-1- $\left[{ }^{14} \mathrm{C}\right]$ triolein than did controls (Table VIII). Lipid-TPN rats had almost $55 \%$ less. When aliquots of the lipid extract were chromatographed, almost all the ${ }^{3} \mathrm{H}$ was in triglyceride. Hepatic ${ }^{14} \mathrm{C}$-lipid content was similar to that of ${ }^{3} \mathrm{H}$ in the experimental groups. The ${ }^{14} \mathrm{C}$ derived data are less specific, as they represent the combined effects of uptake, hydrolysis, oxidation, and resecretion of triglycerides, whereas the ${ }^{3} \mathrm{H}$ content is due to uptake of $\left[{ }^{3} \mathrm{H}\right]$ glycerol triolein and is modified only by subsequent hydrolysis.

The markedly different distribution of the triglyceride fatty acid in the differing dietary states as compared with the similar recoveries of free fatty acid suggested that the lipoprotein lipase activity in these tissues was responsible for the assimilation of triglyceride. The post-heparin plasma lipolytic activities for the control and the two TPN groups were quite different (Table IX). The control and CHO-TPN groups had relatively similar proportions of post-heparin plasma lipolytic activity, which could be attributed to hepatic and peripheral tissue sources (protamine insensitive and sensitive, respectively) (30). However, the CHO-TPN group had increased activities of both, particularly protamine insensitive, in comparison with controls. The Lipid-TPN group had a different partition of post-heparin lipolytic activities into hepatic and peripheral tissue activities. Virtually all of the lipolytic activity was inhibited by pre-incubation with protamine sulfate, and the activity that was protamine sensitive was significantly higher than for the orally fed controls. The differences in post-heparin lipolytic activity observed in the three groups were consistent with differences observed in the lipoprotein-lipase activity extracted from the tissues (Table IX). Lipoprotein lipase activity of adipose tissue was highest in the Lipid-TPN group. Activity in the CHO-TPN rats was lower than in the LipidTPN group but was significantly greater than in the oral controls. The extracts of heart tissue demonstrated significantly greater lipolytic activity in the Lipid-TPN group in comparison with either the oral controls or CHO-TPN group, even for this small number of assays. The extracted lipoprotein lipase from heart did not directly parallel the triglyceride fatty acid recovery data from the heart or the ${ }^{14} \mathrm{CO}_{2}$ generation of the whole animals after intravenous ${ }^{14} \mathrm{C}$-triglyceride. The variance of the muscle lipase activity of the three animals in each group was larger than for the other tissues and did not yield a significant difference between the groups. The Lipid-TPN group had a muscle activity of $1.19 \pm 0.46 \mathrm{nM} / \mathrm{mg}$ per $\mathrm{m}$, the oral controls $0.34 \pm 0.11$, and the CHO-TPN 0.25 \pm 0.12 .

The hepatic content of radiolabeled lipid $1 \mathrm{~h}$ after injection of $1-\left[{ }^{14} \mathrm{C}\right]$ palmitic acid (Table $\mathrm{X}$ ) was significantly increased in both TPN groups as compared with controls and was inversely proportional to the decreased triglyceride secretion in the TPN rats. Thin-layer chromatography demonstrated that $>60 \%$ of the label was in triglyceride. The remainder was in phospholipid. The total body oxidation of $\left[{ }^{14} \mathrm{C}\right]$ palmitic acid was depressed in CHO-TPN rats (Table $\mathrm{X}$ ) but was similar in controls and Lipid-TPN rats. The ${ }^{14} \mathrm{CO}_{2}$ production did not reflect, either directly or inversely, the hepatic lipid ${ }^{14} \mathrm{C}$ content or the lipid content of ${ }^{14} \mathrm{C}$ in muscle (CHO-TPN, 0.09, [0.004]; Lipid-TPN, 0.1 [0.006]); adipose tissue (CHOTPN, 0.8 [0.03]; Lipid-TPN, 0.8 [0.04]); and heart (CHOTPN, 0.3 [0.03]; Lipid-TPN, 0.3 [0.02]) (percent per gram [SEM]) in the 12 Lipid-TPN and 16 CHO-TPN animals studied.

\section{Discussion}

These data confirm other studies showing that TPN can support weight gain and protein anabolism in animals and 

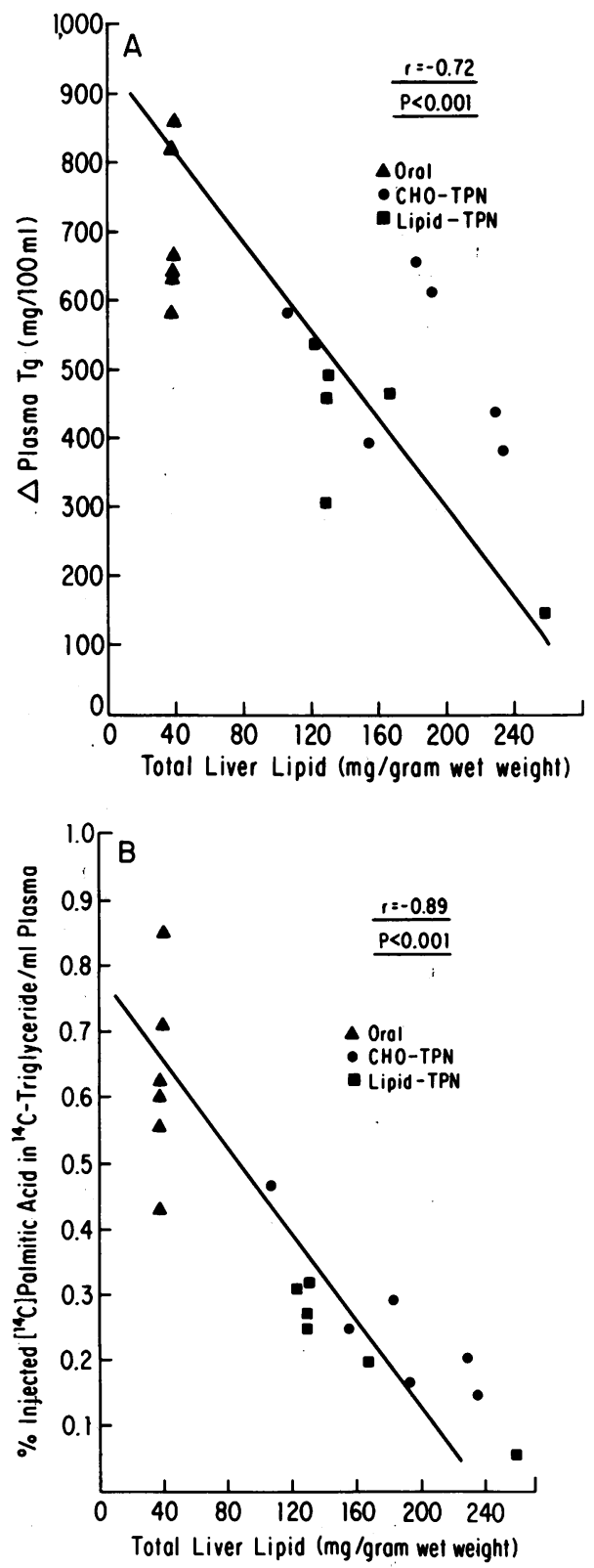

Figure 2. $(A)$ The relationship between the rise in plasma triglyceride concentration (milligrams per deciliter) after administration of intravenous Triton WR1339 and total hepatic lipid content (milligrams per gram wet weight). The rise in plasma triglycerides was calculated from the concentrations $2 \mathrm{~min}$ and $122 \mathrm{~min}$ after Triton was injected. $(B)$ The relationship between the incorporation of 1$\left[{ }^{14} \mathrm{C}\right]$ palmitate into plasma triglyceride (percentage incorporated per milliliter plasma) and total hepatic lipid content (milligrams per gram wet weight) in Tritonized rats. $1-\left[{ }^{14} \mathrm{C}\right]$ palmitate was injected into Tritonized rats $1 \mathrm{~h}$ before they were killed.

man when calories and protein are provided in quantities similar to oral requirements $(1,35)$. It is apparent, however, that in the rat, weight gain was obtained at the cost of hepatic steatosis. Even when dextrose calories were inadequate to support weight gain, hepatic lipid content increased by $60 \%$. Although the prevalence of hepatic steatosis resulting from parenteral feeding in man is unknown, liver biopsies from many patients who develop abnormal liver function tests during TPN show fatty infiltration (2). In addition to the association of steatosis and abnormal function and the possibility of progression to more severe hepatic complications (8), the accumulation of calories as hepatic triglyceride prevents their use by peripheral tissues.

The hypothesis that the increased hepatic triglyceride content in the TPN-fed rats results, in part, from increased fatty acid synthesis is supported by the increase noted in hepatic acetyl-CoA carboxylase activity, the rate limiting step in fatty acid synthesis (36). The fourfold increase in acetyl-CoA carboxylase activity in CHO-TPN rats is comparable to results from rats fed fat-free, high-carbohydrate chow $(37,38)$ or given CHO-TPN (15). Unlike rats given an oral high-fat diet (37, 38) those rats for whom one-third of the dextrose calories were replaced with lipid (Lipid-TPN) did not show depressed acetylCoA carboxylase activity but did show less of a rise in activity than occurred with CHO-TPN. Observed activities of the microsomal enzymes of glycerolipid synthesis in our studies differ from those of reports that show increases in several of the activities after fructose-, glucose-, or fat-enriched diets (39, 40). The minor changes in enzyme activity we observed in TPN-fed rats are unlikely to play a major role in the development of hepatic steatosis and suggest that their normal level of activity can adequately deal with the increased quantity of newly synthesized fatty acid present under these experimental conditions.

Increased uptake of free fatty acids mobilized from adipose tissue could enhance hepatic triglyceride synthesis; however, this is improbable since the dextrose content of both TPN solutions would induce insulin release and suppress adipose tissue lipolysis. The low percentage of linoleic acid in the CHO-TPN liver triglyceride also supports the concept of endogenous synthesis from dextrose-derived precursors rather than from adipose tissue fatty acids, as the latter contain appreciable amounts of linoleate (41).

The impaired hepatic triglyceride secretion seen after both TPN regimens showed a high correlation with the total hepatic lipid content and is probably of fundamental importance in the development of steatosis. The difference between the triglyceride mass data and the secretion of ${ }^{14} \mathrm{C}$-triglyceride may be due to the contribution of intestinally synthesized triglyceride. As much as $6 \mathrm{mg} / \mathrm{h}$ may be secreted into the intestinal lymph of a $300-400-\mathrm{g}$ rat in the fasted state (42). The difference may also be due to the increased quantities of newly synthesized hepatic fatty acid and increased amounts of triglyceride fatty acid after CHO-TPN, which compete with the exogenous $1-\left[{ }^{14} \mathrm{C}\right]$ palmitate, producing spuriously low hepatic triglyceride secretion rates. Although CHO-TPN produced a larger increment in plasma triglyceride after Triton and a higher hepatic acetyl-CoA carboxylase specific activity and hepatic triglyceride 
Table VII. Plasma Triglyceride Concentration, Plasma Lipid Content of ${ }^{14} \mathrm{C}$ and ${ }^{3} \mathrm{H}$, and Secretion of Re-esterified Triglyceride Fatty Acid in TPN and Chow-fed Rats 20 min after Intravenous Injection of $2-\left[{ }^{3} \mathrm{H}\right]$ Glycerol-1- $\left[{ }^{14} \mathrm{C}\right]$ Triolein

\begin{tabular}{|c|c|c|c|c|c|}
\hline \multirow[b]{2}{*}{ Regimen } & \multirow[b]{2}{*}{$\begin{array}{l}\text { Plasma } \\
\text { triglyceride }\end{array}$} & \multicolumn{2}{|c|}{ Plasma lipid radiolabeled content } & \multirow{2}{*}{$\begin{array}{l}{ }^{3} \mathrm{H} /{ }^{14} \mathrm{C} \\
\text { ratio } \pm \text { SEM }\end{array}$} & \multirow[b]{2}{*}{$\begin{array}{l}\text { Secretion of re-esterified } \\
{ }^{14} \mathrm{C} \text {-fatty acid }\end{array}$} \\
\hline & & ${ }^{3} \mathrm{H}$ & ${ }^{14} \mathrm{C}$ & & \\
\hline & $m g / d l \pm S E M$ & $\%$ dose/ml $\pm S E M$ & $\%$ dose $/ m / \pm S E M$ & & $\%{ }^{14} \mathrm{C}$ secreted $/ \mathrm{ml}$ in $20 \mathrm{~min} \pm S E M$ \\
\hline \multicolumn{6}{|c|}{ Oral control } \\
\hline$(n=5)$ & $22.7 \pm 2.59$ & $0.080 \pm 0.010$ & $0.218 \pm 0.013$ & $1.88 \pm 0.16$ & $0.138 \pm 0.007$ \\
\hline \multicolumn{6}{|l|}{ CHO-TPN } \\
\hline$(n=7)$ & $21.2 \pm 1.40$ & $0.088 \pm 0.005$ & $0.167 \pm 0.014$ & $2.53 \pm 0.085 \ddagger$ & $0.079 \pm 0.015 \ddagger$ \\
\hline \multicolumn{6}{|l|}{ Lipid-TPN } \\
\hline$(n=7)$ & $22.3 \pm 0.41$ & $0.804 \pm 0.089^{*}$ & $0.867 \pm 0.101^{*}$ & $5.05 \pm 0.196^{*}$ & $0.062 \pm 0.015 \ddagger$ \\
\hline
\end{tabular}

* Different from oral and CHO-TPN, $P<0.01$. $¥$ Different from oral, $P<0.05$.

mass than did Lipid-TPN, both groups had a similar suppression of $1-\left[{ }^{14} \mathrm{C}\right]$ palmitate incorporation into plasma triglyceride. These data do not support the possibility that increased competition between exogenous $1-\left[{ }^{14} \mathrm{C}\right]$ palmitate and the pool of hepatic triglyceride fatty acid produced a spurious underestimate of hepatic secretion, since competition would reduce 1-[ $\left[{ }^{14} \mathrm{C}\right]$ palmitate incorporation more after CHO-TPN than after Lipid-TPN.

The mechanism by which TPN suppresses triglyceride secretion is poorly understood. Hepatic toxins and choline deficiency also appear to produce steatosis by suppressing triglyceride secretion $(43,44)$. CHO-TPN did not include choline, but Lipid-TPN contained appreciable amounts of phosphatidylcholine and both regimens supplied adequate quantities of methionine. In a subsequent study the addition of choline to CHO-TPN solution did not reduce steatosis or increase the triglyceride secretion (Hall, R. I., unpublished observation). Essential fatty acid deficiency develops rapidly in humans receiving fat-free TPN (14) and may affect hepatic triglyceride secretion (45). Essential fatty acid deficiency takes $>10 \mathrm{wk}$ to develop in the orally fed rat (46) and is unlikely to have played a role in the development of steatosis, since ample linoleate was provided in the Lipid-TPN. Hepatic triglyceride secretion depends upon availability of adequate amounts of the protein moiety of plasma lipoproteins. It is suggested that the hepatic steatosis found in Kwashiorkor is due to deficient hepatic production of this protein (47), and a similar mechanism may be responsible for reduced triglyceride secretion during TPN. Apolipoprotein-C has an important regulatory role in the partitioning of plasma triglyceride between the liver and peripheral tissues (33). Qualitative analysis of plasma apolipoproteins in rats after CHO-TPN and Lipid-TPN, and after oral chow showed definite differences in apoprotein content between the groups, but neither TPN group was deficient in C-apoproteins (Quarfordt, S. H., unpublished observation). In addition to the effect of TPN on plasma triglyceride secretion,

Table VIII. The Hepatic Recovery of Radiolabeled Lipid and of ${ }^{14} \mathrm{CO}_{2}$ in Expired Air 20 min after the Intravenous Injection of $2-\left[{ }^{3} \mathrm{H}\right]$ Glycerol- $-\left[-\left[{ }^{14} \mathrm{C}\right]\right.$ Triolein

\begin{tabular}{|c|c|c|c|c|c|c|}
\hline \multirow[b]{2}{*}{ Regimen } & \multicolumn{2}{|c|}{ Recovery of ${ }^{3} \mathrm{H}$ and ${ }^{14} \mathrm{C}$ in liver lipid extract } & \multicolumn{3}{|c|}{ Recovery of ${ }^{14} \mathrm{C}$ in lipid extract of tissues } & \multirow{2}{*}{$\begin{array}{l}{ }^{14} \mathrm{C} \text { expired } \\
\text { in } \mathrm{CO}_{2} \text { after } \\
20 \mathrm{~min}\end{array}$} \\
\hline & ${ }^{3} \mathrm{H}$ & ${ }^{14} \mathrm{C}$ & Muscle $(n=5)$ & Adipose $(n=5)$ & Heart $(n=5)$ & \\
\hline & $\% / g$ liver $\pm S E M$ & $\% / g$ liver $\pm S E M$ & $\% / g \pm S E M$ & $\% / g \pm S E M$ & $\% / g \pm S E M$ & $\% \pm S E M$ \\
\hline $\begin{array}{l}\text { Oral contro } \\
\quad(n=5)\end{array}$ & $0.966 \pm 0.065$ & $3.692 \pm 0.144$ & $0.11 \pm 0.024$ & $0.36 \pm 0.071$ & $1.49 \pm 0.348$ & $9.6 \pm 0.96$ \\
\hline $\begin{array}{c}\text { CHO-TPN } \\
\quad(n=6)\end{array}$ & $1.344 \pm 0.126 \ddagger$ & $4.576 \pm 0.474$ & $0.08 \pm 0.006$ & $2.10 \pm 0.122^{\|}$ & $0.29 \pm 0.0017 \pi$ & $27+0.34^{\prime \prime}$ \\
\hline $\begin{array}{l}\text { Lipid-TPN } \\
\quad(n=7)\end{array}$ & $0.414 \pm 0.033 \S$ & $1.472 \pm 0.089 \S$ & $0.22 \pm 0.028 \S$ & $1.56 \pm 0.190^{H \prime}$ & $0.69 \pm 0.077^{* *}$ & $6.4 \pm 0.64$ \\
\hline
\end{tabular}

* Muscle and heart data are expressed as percent per gram wet weight. Adipose data are expressed as percent per gram lipid. $¥$ Different from oral, $P<0.05$. § Different from oral and from CHO-TPN, $P<0.01$. "Different from oral, $P<0.01$. " Different from oral, $P<0.01$ and from Lipid-TPN, $P<0.05$. ** Different from oral, $P<0.05$ and from CHO-TPN, $P<0.01$. 
Table IX. Post-Heparin Lipolytic and Tissue Lipoprotein Lipase Activities in TPN and Chow-fed Rats

\begin{tabular}{|c|c|c|c|c|c|}
\hline \multirow[b]{2}{*}{ Regimen } & \multicolumn{3}{|c|}{ Post-heparin lipolytic activity } & \multicolumn{2}{|c|}{ Tissue lipoprotein lipase specific activity } \\
\hline & Protamine insensitive & Protamine sensitive & $\%$ of total & Adipose & Heart \\
\hline & $\mu M / m l$ per $h \pm S E M$ & $\mu M / m l$ per $h \pm S E M$ & & $\begin{array}{l}\mu M / m g \text { protein } \\
\text { per min } \pm S E M\end{array}$ & $\begin{array}{l}\mu M / m g \text { protein } \\
\text { per min } \pm S E M\end{array}$ \\
\hline Oral controls $(n=3)$ & $17.7 \pm 2.8$ & $7.6 \pm 1.9$ & 30.0 & $5.24 \pm 0.89$ & $4.3 \pm 0.52$ \\
\hline CHO-TPN $(n=3)$ & $32.5 \pm 1.8^{*}$ & $14.4 \pm 2.5$ & 30.7 & $12.73 \pm 0.66^{\| \prime}$ & $5.1 \pm 0.55$ \\
\hline Lipid-TPN $(n=3)$ & $5.3 \pm 1.4 \ddagger$ & $23.1 \pm 1.5 \S$ & 81.3 & $32.09 \pm 7.30 \pi$ & $9.4 \pm 0.30^{* *}$ \\
\hline
\end{tabular}

* Different from oral, $P<0.01$, and from Lipid-TPN, $P<0.001$. $\ddagger$ Different from oral, $P<0.02$. $\S$ Different from oral, $P<0.01$, and from CHO-TPN, $P<0.05$. "Different from oral, $P<0.05$, and from Lipid-TPN, $P<0.05$. $\pi$ Different from oral, $P<0.02$. ${ }^{* *}$ Different from oral, $P<0.01$, and from CHO-TPN, $P<0.01$.

the absence of any oral intake probably reduces the hormoneinduced secretion of bile. Reduced secretion of fatty acid groups as biliary phospholipid may result in a greater availability of hepatic fatty acid for esterification to triglyceride.

Enhanced hepatic uptake of plasma triglyceride after $\mathrm{CHO}$ TPN and reduced uptake after Lipid-TPN may modulate the degree of steatosis. Triglyceride uptake does not apper to be a prime determinant, however, since the overall effect of changes in the rate of uptake were small and correlated poorly with hepatic lipid content $(r=0.04)$. Although the post-heparin hepatic lipase activity correlated directly with hepatic $\left[{ }^{3} \mathrm{H}\right]$ glycerol-triolein recovery it is uncertain whether increased lipase activity is a consequence or a cause of the enhanced triglyceride uptake. Despite the lack of reasons for the differing uptake of plasma triglyceride by the liver it was clear that because of the differing hepatic access, this lipid was not distributed to peripheral tissues as effectively after CHO-TPN as after Lipid-TPN.

The plasma recovery of triglyceride emulsion was greater after 20 min in the animals maintained with lipid TPN than with CHO-TPN or oral chow. This relatively late period reflects not only peripheral tissue assimilation but also subsequent hepatic uptake. The peripheral tissue lipoprotein lipase

Table X. The Hepatic Recovery of Radiolabeled Lipid and of ${ }^{14} \mathrm{CO}_{2}$ in Expired Air 60 min after Intravenous Injection of $1-\left[{ }^{14} \mathrm{C}\right]$ Palmitic Acid

\begin{tabular}{lll}
\hline Regimen & $\begin{array}{l}\text { Recovery of }{ }^{14} \mathrm{C} \text { in } \\
\text { hepatic lipid extract }\end{array}$ & $\begin{array}{l}{ }^{14} \mathrm{C} \text { in expired } \mathrm{CO}_{2} \\
\text { after } 60 \mathrm{~min}\end{array}$ \\
\hline & $\% / g$ liver $\pm S E M$ & $\% \pm S E M$ \\
Oral $(n=6)$ & $0.63 \pm 0.10$ & $20.8 \pm 2.17$ \\
CHO-TPN $(n=12)$ & $2.15 \pm 0.13^{*}$ & $11.3 \pm 0.88 \ddagger$ \\
Lipid-TPN $(n=14)$ & $2.01 \pm 0.07^{*}$ & $20.6 \pm 1.06$ \\
\hline
\end{tabular}

* Different from oral, $P<0.001$.

$\ddagger$ Different from oral and from Lipid-TPN, $P<0.001$. and the post-heparin protamine sensitive lipolytic activities were both increased after the Lipid-TPN regimens, indicating that diminished activity of this enzyme could not be responsible for the slower clearance. Recoveries of triglyceride fatty acid in peripheral tissue were also greater than or equal to recoveries in the controls. The decreased hepatic recovery of triglyceride fatty acid, as well as the significantly lower hepatic lipase, was probably the most significant factor in the delayed plasma clearance of triglyceride particles after Lipid-TPN.

Even though the triglyceride emulsion was cleared from the plasma more slowly in the Lipid-TPN group, its recovery in a rapidly metabolizing tissue such as the heart was greater than after CHO-TPN. The significantly greater heart lipoprotein lipase activity in the Lipid-TPN than in the CHO-TPN animals may have been responsible for the greater recovery of triglyceride fatty acid in this organ. The ${ }^{14} \mathrm{CO}_{2}$ production from radiolabeled triglyceride closely followed the heart tissue ${ }^{14} \mathrm{C}$ lipid recovery and suggested that for this interval the heart was an important organ in the burning of this fuel. The enhanced recovery of the triglyceride fatty acid in adipose tissue of both TPN groups also correlated with enhanced adipose lipoprotein lipase activity as compared with that of controls. However, the significantly greater adipose lipase of the Lipid-TPN than of the CHO-TPN was not accompanied by a greater recovery of plasma triglyceride fatty acid in this tissue. The information at hand gives no reasons for this discrepancy.

The addition of lipid as a nonprotein calorie source had an impressive effect on lipolytic activities in liver and peripheral tissue. The significantly lower hepatic lipase activity in comparison with activity in CHO-TPN or oral controls has no mechanistic explanation. The enhanced adipose lipolytic activities with CHO-TPN and Lipid-TPN may relate to increased plasma insulin levels seen with TPN (48) and the known effect of this hormone on lipoprotein lipase (49). The net effect on plasma triglyceride lipolysis of lipid supplementation to TPN is a shift in plasma triglyceride catabolism to favor peripheral tissues over liver. This is probably one reason for there being 
less radiolabeled plasma triglyceride recovered in the liver with Lipid-TPN, but the access of plasma triglyceride to the liver is also importantly influenced by its apoprotein content (33).

The development of hepatic steatosis after both CHO-TPN and Lipid-TPN was most directly related to increased synthesis of fatty acid and impaired hepatic release of triglyceride. The addition of lipid to a TPN regimen has a beneficial effect in terms of distributing the triglyceride fatty acid molecules from the liver to peripheral tissue. Peripheral lipolytic enzymes were activated and the hepatic lipase and the access to the liver were apparently reduced. This effect, along with the enhanced catabolism of fatty acid and the attenuated synthesis of fatty acid in the liver when lipid supplementation was provided, strongly suggests that calories in this form should reduce the hepatic steatotic complications. Biopsy studies in man suggest that hepatic steatosis is reduced when lipid emulsions provide a substantial proportion of the calories in TPN regimens (6, 12). Animal experiments have indicated that the TPN regimens likely to cause the least steatosis provide $\sim 25 \%$ of the nonprotein calories as lipid (50). Our observations have confirmed that there is less accumulation of hepatic triglyceride as a result of TPN with lipid than as a result of only carbohydrate as a nonprotein calorie source, and we have suggested reasons for this effect.

\section{Acknowledgments}

We gratefully acknowledge Elaine B. Haynes, Mary Ruth Greenfield, Marjorie Bell, and Dr. B. S. Kitchell for technical assistance, and Sue Younkin for typing the manuscript.

R. I. Hall is supported in part by the Travenol Travelling Fellowship in Nutrition (Travenol Laboratories, Ltd., London) and a grant from the Wellcome Trust. This work was supported by Veterans Administration research grants (Dr. Quarfordt) and by March of Dimes Defects Foundation grant 1-850 and National Institutes of Health grant HL25927 (Dr. Coleman).

\section{References}

1. Dudrick, S. J., D. S. Wilmore, H. M. Vars, and J. E. Rhoads. 1968. Long-term total parenteral nutrition with growth development and positive nitrogen balance. Surgery. 64:134-142.

2. Sheldon, G. F., S. R. Petersen, and R. Sanders. 1978. Hepatic dysfunction during hyperalimentation. Arch. Surg. 113:504-508.

3. Postuma, R., and C. L. Trevenen. 1979. Liver disease in infants receiving total parenteral nutrition. Pediatrics. 63:110-115.

4. Touloukian, R. G., and J. H. Seashore. 1975. Hepatic secretory obstruction with total parenteral nutrition in the infant. J. Pediatr. Surg. 10:353-360.

5. Grant, J. P., C. E. Cox, L. M. Kleinman, M. M. Maher, M. A. Pittman, J. A. Tangrea, J. M. Brown, E. Gross, R. M. Beazley, and R. S. Jones. 1977. Serum hepatic enzyme and bilirubin elevations during parenteral nutrition. Surg. Gynecol. Obstet. 145:573-580.

6. Tulikouri, I., and K. Muikuri. 1982. Morphological fatty changes and function of the liver, serum free fatty acids and triglycerides during parenteral nutrition. Scand. J. Gastroenterol. 17:177-185.
7. Dahms, B. B., and T. C. Halpin. 1981. Serial liver biopsies in parenteral nutrition-associated cholestasis of early infancy. Gastroenterology. 81:136-144.

8. Cohen, C., and M. M. Olsen. 1981. Pediatric total parenteral nutrition. Liver histopathology. Arch. Pathol. Lab. Med. 105:152-156.

9. Burke, J. F., R. R. Wolfe, C. J. Mullany, D. E. Mathews, and D. M. Bier. 1979. Glucose requirements following burn injury. Ann. Surg. 190:274-285.

10. Parsa, N. M., J. F. Ferrer, and D. Mabif. 1974. Safe central venous nutrition. Guidelines for prevention and management of complications. Charles C. Thomas, Publisher, Springfield, IL. 232-239.

11. Koga, Y., K. Ikeda, and K. Inokuchi. 1975. Effect of complete parenteral nutrition using fat emulsion on liver. Ann. Surg. 181:186190.

12. McDonald, A. T. J., M. J. Phillips, and K. N. Jeejeebhoy. 1973. Reversal of fatty liver by Intralipid in patients on total parenteral nutrition. Gastroenterology. 64:885.

13. McFayden, B. V., S. J. Dudrick, G. Baguero, and E. T. Gum. 1979. Clinical and biological changes in liver function during intravenous hyperalimentation. J.P.E.N. 3:438-443.

14. Stein, T. P., G. P. Buzby, W. C. Hargrove, M. J. Leskiev, and J. L. Mullen. 1980. Essential fatty acid deficiency in patients receiving simultaneous parenteral and oral nutrition. J.P.E.N. 4:343-345.

15. Kaminski, D. L., A. Adams, and M. Jellinek. 1980. The effect of hyperalimentation on hepatic lipid content and lipogenic enzyme activity in rats and man. Surgery. 88:93-100.

16. Popp, M. B., and M. F. Brennan. 1981. Long-term vascular access in the rat: importance of asepsis. Am. J. Physiol. 241(Heart. Circ. Physiol. 10):H606-H612.

17. Tietz, N. W. 1976. Fundamentals of Clinical Chemistry. W.B. Saunders, Philadelphia. 300-302.

18. Dole, V. P., and M. Meinerty. 1960. Microdetermination of long-chain fatty acids in plasma and tissues. J. Biol. Chem. 235:25952599.

19. Kessler, G., and H. Lederer. 1966. Fluorometric measurement of triglycerides. In Automation in Analytical Chemistry. Technicon Symposia, 1965. L. T. Skeggs, editor. Mediad, Inc., New York. 1966. 341-344.

20. Ames, B. N., and Dubin, D. T. The role of polyamines in the neutralization of bacteriophage deoxyribonucleic acid. J. Biol. Chem. 235:769-775.

21. Karmen, A., M. Whyte, and D. S. Goodman. 1963. Fatty acid esterification and chylomicron formation during fat absorption I. Triglycerides and cholesterol esters. J. Lipid Res. 4:312-321.

22. Craig, M. C., R. E. Dugan, R. A. Muesing, L. L. Slakey, and J. W. Porter. 1972. Comparative effects of dietary regimes on the levels of enzymes regulating the synthesis of fatty acids and cholesterol in rat livers. Arch. Biochem. Biophys. 151:128-136.

23. Lowry, O. H., N. J. Rosebrough, A. L. Farr, and R. J. Randall. 1951. Protein measurement with the folin-phenol reagent. J. Biol. Chem. 193:265-275.

24. Banis, R. J., and S. B. Tove. 1974. Solubilization of a longchain fatty acyl CoA synthetase from chickens adipose tissue microsomes. Biochem. Biophys. Acta. 348:210-220.

25. Schlossman, D. M., and R. M. Bell. 1976. Triacylglycerol synthesis in isolated fat cells. Evidence that the sn-glycerol-3-phosphate and dihydroxyacetone phosphate acyltransferase activities are dual catalytic functions of a single microsomal enzyme. J. Biol. Chem. 251:5738-5744. 
26. Lands, W. E. M., and P. Mart. 1965. Metabolism of glycerolipids. J. Biol. Chem. 240:1905-1911.

27. Mavis, R. D., J. N. Finkelstein, and B. P. Hall. 1978. Pulmonary surfactent synthesis. A highly active microsomal phosphatidate phosphohydrolase in the lung. J. Lipid Res. 19:467-477.

28. Coleman, R., and R. M. Bell. 1976. Triacylglycerol synthesis in isolated fat cell studies on the microsomal diacylglycerol acyltransferase activity using ethanol-dispersed diacylglycerols. J. Biol. Chem. 251:4537-4543.

29. Coleman, R., and R. M. Bell. 1977. Phospholipid synthesis in isolated fat cells. Studies of microsomal diacylglycerol cholinephosphotransferase and diacylglycerol ethanolaminephosphotransferase activities. J. Biol. Chem. 252:3050-3056.

30. Krauss, R. M., H. C. Windmueller, R. I. Levy, and D. S. Frederickson. 1973. Selective measurement of two different triglyceride lipase activities in rat post-heparin plasma. J. Lipid Res. 14:286-295.

31. Schotz, M. C., A. S. Garfinkel, R. J. Heuboltter, and J. E. Stewart. 1970. A rapid assay for lipoprotein lipase. J. Lipid Res. 11:6869.

32. Byers, S. O., and M. Friedman. 1959. Site of origin of plasma triglyceride. Am. J. Physiol. 198:629-631.

33. Shelburne, F., J. Hanks, W. Meyers, and S. Quarfordt. 1980. Effect of apoprotein on hepatic uptake of triglyceride emulsions in the rat. J. Clin. Invest. 65:652-658.

34. Warner, R. G., and L. H. Breuer, Jr. 1972. Nutrient requirements of the laboratory rat. In Nutrient Requirements of Laboratory Animals. No. 10. Printing and Publishing Office, National Academy of Sciences, Washington DC. 56-93.

35. Dudrick, S. J., D. W. Wilmore, H. M. Vars, and J. E. Rhoads. 1969. Can intravenous feeding as the sole means of nutrition support growth in the child and restore weight loss in an adult? An affirmative answer. Ann. Surg. 169:974-984.

36. Bortz, W. S., W. Abraham, and I. L. Chackoff. 1963. Localization of the block in lipogenesis resulting from feeding rat. J. Biol. Chem. 238:1266-1272.

37. Bloch, K., and D. Vance. 1977. Control mechanisms in the synthesis of saturated fatty acids. Ann. Rev. Biochem. 46:263-298.

38. Numa, S., and S. Yamashita. 1975. Regulation of lipogenesis in animal tissues. Curr. Top. Cell Regul. 8:197-246.

39. Brindly, D. N. 1977. Regulation of fatty acid esterification in tissues. In Regulation of Fatty Acid and Glycerolipid Metabolism. R. Dils and J. Knudson, editors. Pergamon Press Ltd., Oxford. 31-40.

40. Brindly, D. N., and R. G. Sturton. 1982. Phosphatide metabolism and its relation to triacylglycerol biosynthesis. In Phospholipids. J. N. Hawthorne and G. B. Ansell, editors. Elsevier Biomedical Press, Amsterdam. 179-213.

41. Brodie, B. B., W. M. Butler, M. G. Horning, R. P. Maickel, and H. M. Maling. 1961. Alcohol-induced triglyceride deposition in liver through derangement of fat transport. Am. J. Clin. Nutr. 9:432435.

42. Ockner, R. K., F. B. Hughes, and K. J. Isselbacher. 1969. Very low density lipoproteins in intestinal lymph: origin, composition, and role in lipid transport in the fasting state. J. Clin. Invest. 48:20792088.

43. Lonbardi, B., and R. O. Recknagel. 1962. Interference with secretion of triglycerides by the liver as a common factor in toxic liver injury. Am. J. Pathol. 40(Suppl. 5):571-586.

44. Mookerjea, S. 1971. Actions of choline in lipoprotein metabolism. Fed. Proc. 30:143-150.

45. Jeejeebhoy, K. N., W. J. Zohrab, B. Langer, M. J. Phillips, A. Kuksis, and G. Anderson. 1973. Total parenteral nutrition at home for 23 months without complication, and good rehabilitation. A study of technical and metabolic features. Gastroenterology. 65:811-820.

46. Sinclair, A. J., and F. D. Collins. 1968. Fatty livers in rats difficient in essential fatty acids. Biochem. Biophys. Acta. 152:498509.

47. Truswell, A. S., J. D. Hensen, C. E. Watson, and P. Wannenburg., 1969. Relations of serum lipids and lipoprotein to fatty liver in Kwashiorkor. Am. J. Clin. Nutr. 22:568-76.

48. Jeejeebhoy, K. N., G. H. Anderson, A. F. Nakhooda, C. R. Greenberg, I. Sanderson, and E. B. Marliss. 1976. Metabolic studies in total parenteral nutrition with lipid in man. Comparison with glucose. J. Clin. Invest. 57:125-136.

49. Borensztain, J., D. R. Samols, and A. H. Rubenstein. 1972. Effect of insulin on lipoprotein lipase activity in the rat heart and adipose tissue. Am. J. Physiol. 223:1271-1275.

50. Buzby, G. P., J. Mullen, T. P. Stein, and E. F. Rosato. 1981. Manipulation of TPN calorie substrate and fatty infiltrations of the liver. J. Surg. Res. 31:46-54. 